\title{
An Active-Rectification Based Communication Free Inductive Power Transfer for Battery Charging System with Soft-Switching Capability
}

Dou, Yi; Liu, Yunfeng; Huang, Xiaosheng; Ouyang, Ziwei; Andersen, Michael A.E.

Published in:

Proceedings of 35th Annual IEEE Applied Power Electronics Conference and Exposition

Link to article, DOI:

10.1109/APEC39645.2020.9124058

Publication date:

2020

Document Version

Peer reviewed version

Link back to DTU Orbit

Citation (APA):

Dou, Y., Liu, Y., Huang, X., Ouyang, Z., \& Andersen, M. A. E. (2020). An Active-Rectification Based

Communication Free Inductive Power Transfer for Battery Charging System with Soft-Switching Capability. In Proceedings of 35th Annual IEEE Applied Power Electronics Conference and Exposition (pp. 1627-1633). [9124058] IEEE. https://doi.org/10.1109/APEC39645.2020.9124058

\section{General rights}

Copyright and moral rights for the publications made accessible in the public portal are retained by the authors and/or other copyright owners and it is a condition of accessing publications that users recognise and abide by the legal requirements associated with these rights.

- Users may download and print one copy of any publication from the public portal for the purpose of private study or research.

- You may not further distribute the material or use it for any profit-making activity or commercial gain

- You may freely distribute the URL identifying the publication in the public portal 


\title{
An Active-Rectification Based Communication Free Inductive Power Transfer for Battery Charging System with Soft-Switching Capability
}

\author{
${ }^{1}$ Yi Dou, ${ }^{1}$ Yunfeng Liu, ${ }^{1,2}$ Xiaosheng Huang, ${ }^{1}$ Ziwei Ouyang and ${ }^{1}$ Michael A.E. Andersen \\ ${ }^{1}$ Department of Electrical Engineering \\ Technical University of Denmark \\ Kgs. Lyngby, Denmark \\ ${ }^{2}$ College of Information Science and Engineering \\ Fujian University of Technology \\ Fuzhou, China \\ yidou, yunliu, xihuang, zo, ma@elektro.dtu.dk
}

\begin{abstract}
Inductive Power transfer (IPT) is rapidly developed for power conversion to batteries because of its high convenience, high safety and low operation cost. However, the output regulation of IPT system is of great complexity with maintaining softswitching operation by conventional methods. In this paper, an inductive power transfer system for battery charging applications are proposed to achieve output regulation by only secondaryside control without the wireless communication. Besides, the proposed system can realize soft-switching on the primary-side to further reduce the power loss and the EMI issues. The system operates at a constant switching frequency and by a monotonic output regulation to maintain a high stability during the power conversion. The circuit operation analysis, proposed output regulation method and the hardware implementation are analyzed. In order to verify the proposed system, a $1 \mathrm{~kW}$ IPT prototype is built and its peak efficiency achieve $96.8 \%$ at 330 V/ 3 A output.
\end{abstract}

Index Terms-Inductive power transfer; Series-series compensation; secondary-side control; Active-rectification; Battery charging syste

\section{INTRODUCTION}

Inductive power transfer (IPT) is regarded as an evolutional battery charging method for industrial applications, such as automatic guided vehicles and industrial robots. Among all the wireless battery charging systems, the output regulation is of great importance to follow the battery-charging scheme for a longer lifetime and higher operation safety during the charging.

A typical wireless charging system is illustrated in Fig.1 (a), which consists of a PFC converter, an inductive power transfer system and a DC-DC converter. The DC-DC power converter cascaded after the IPT system is to achieve the output regulation for the battery, but the multi-stages structure limits the systems' charging efficiency [1]-[4]. Thus, several control strategies for IPT system are investigated to achieve the output regulation with wireless communication between the primary side and the secondary side [5]-[8]. In this way, the number of power stages can be reduces as two to further push the efficiency to be higher, as illustrated in Fig.1 (b). Nevertheless, in

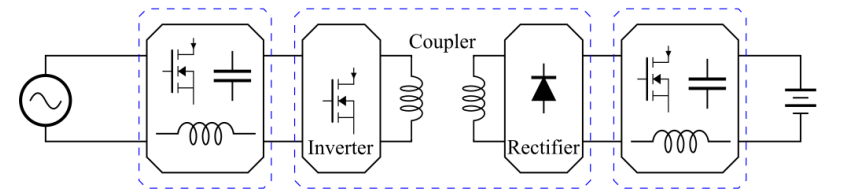

$\begin{array}{llll}\text { AC Source } & \text { PFC } & \text { IPT System } & \text { DC-DC Converter Battery load }\end{array}$

(a)

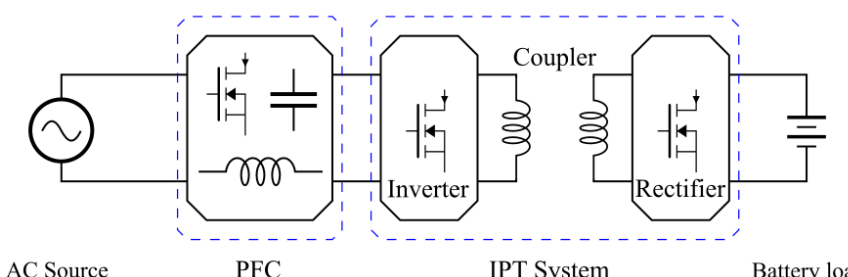

(b)

Fig. 1. (a) Conventional 3-stage IPT charging system (b) 2-stage IPT charging system with active rectifier.

the complex industrial environment with much conductive and radiation EMI noisy, the high-speed wireless communication may be interfered, which leading to severe safety issues from unstable operation during the charging period. In [9], [10], two different output regulation strategies for IPT systems are proposed without wireless communication but need two independent micro-controller at both primary side and secondary side. The requirement of the controllers limits their widespread use due to high system's and complexity of implementation. In this paper, a novel communication-free inductive power transfer system with soft-switching capability is proposed and verified by experimental results. By the proposed secondaryside control, the output regulation of the IPT system can be achieved by phase-shift control in a specified switching frequency. Moreover, the ZVS turn-on for the switches at the primary-side can be realized to reduce the power loss and the EMI interfere will also be decreased. The theory analysis of 


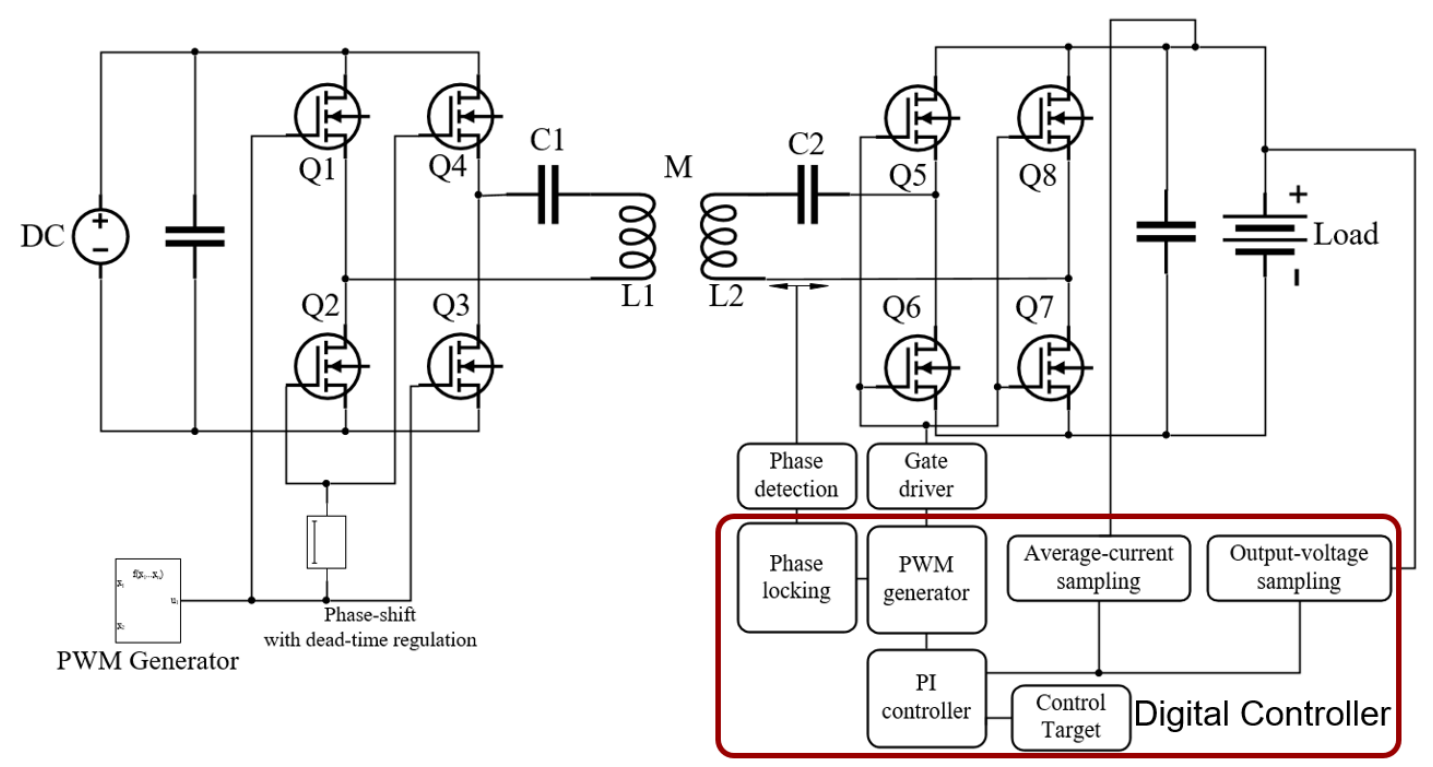

Fig. 2. Proposed IPT system with secondary output regulation.

the proposed system is presented in section II and the hardware implementation isintroduced in section III. In section IV, the experimental results are given to verify the proposed concept and the section $\mathrm{V}$ concludes the paper.

\section{System Structure And Output Regulation}

\section{A. Proposed System Structure}

The proposed IPT system, including a power source, an inverter, a pair of coupled coils, with series-series (S-S) compensation, an active rectifier with sampling circuit and controller, and the load, is illustrated in Fig.1. The operating frequency of the inverter is design to satisfy

$$
\omega_{r}=\frac{1}{\sqrt{L_{1} C_{1}}}=\frac{1}{\sqrt{L_{2} C_{2}}}
$$

, where $\omega_{r}$ is the operational frequency of the inverter; $L_{1}$ and $L 2$ are the self-inductance of the primary coil and secondary coil correspondinglu; and $C_{1}$ and $C_{2}$ are the compensation capacitance of primary-side and secondary-side.

The operating switching frequency of the rectifier at the secondary side is depended on the switching frequency of the inverter by sampling the secondary current. All the sampling circuits and the controller of the proposed system locate on the secondary side thus no wireless communication is needed for the system.

\section{B. Output Regulation by Active Rectifier with Current Source Input}

The circuit of active rectifier with phase-shift control and its key waveforms excited by a sinusoidal current source are illustrated in Fig.2. As shown in Fig.3 (a), due to the reversed diodes are intrinsically paralleled with the MOSFETs, the output of the current source is maintained continuous (in red in Fig.3 (b)) while the phase-shift between two half-bridge

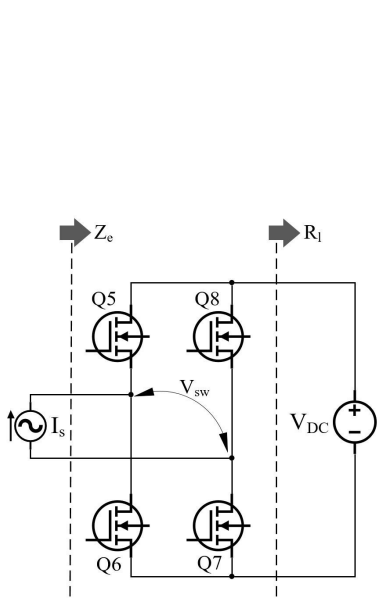

(a)

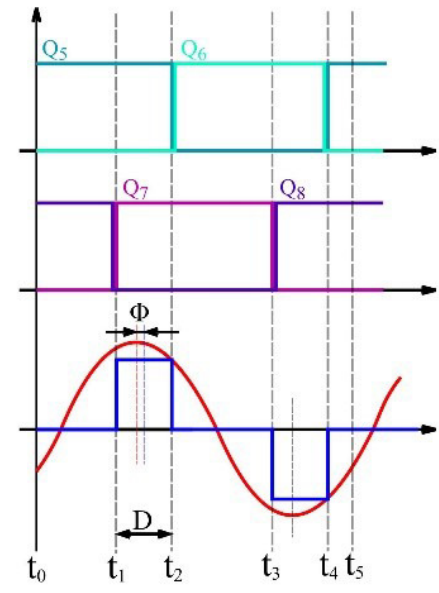

(b)
Fig. 3. (a) Equavalent circuit of secondary active rectifier (b) Key wavefroms of secondary active rectifier.

$\left(Q_{5} / Q 6\right.$ and $\left.Q_{7} / Q 8\right)$ can determine the power transferred to the load. Thus, two control variables, the duty-cycle $D$ and the phase-shift between the current and the voltage $\left(V_{S W}\right)$ can be the controlled to regulate the output of the active rectifier.

\section{Decoupling Primary-side and Secondary-Side by S-S Com- pensation}

With the series capacitors resonating with the selfinductance of the coil, the input of the secondary-side can be decoupled as a constant current source, if the mutual inductance of the coils and the input voltage can be maintained as constant. With the first-harmonic-analysis (FHA) conducted on the circuit, an $\mathrm{AC}$ equivalent circuit at switching frequency $\left(\omega_{r}\right)$ is illustrated in Fig.4, in which $V_{1}$ is the voltage of the output of the inverter; $R_{1}$ is the equivalent series resistance in 
the primary-side; $R_{2}$ is the equivalent series resistance in the secondary-side; and $V_{2}$ is the equivalent $\mathrm{AC}$ voltage of the input for the rectifier $\left(V_{S W}\right.$ in Fig.3 (a)). Correspongdly, the equivalent load impedance $\left(Z_{L}\right)$, the reverse impedance $\left(Z_{R}\right)$ and the input impedance of the inverter $\left(Z_{i n}\right)$ are also marked.

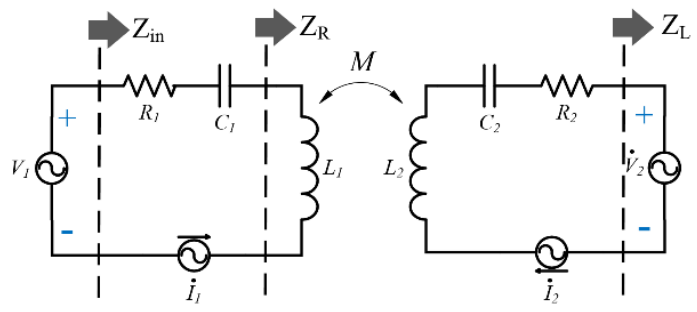

Fig. 4. FHA equivalent circuit of IPT with S-S compensation.

Based on the equivalent circuit, the operation of the system can be decribed by

$$
\begin{gathered}
\beta_{i n}(\omega t)=\frac{i_{i n 1}(\omega t)}{V_{i n} \omega C_{f}} \\
=\left\{\begin{array}{cc}
\beta_{I D C}-\beta_{i n}(\omega t+\pi) & 0<\omega t \leq \pi \\
\frac{d v_{S n}(\omega t)}{d \omega t}-q_{e}^{2} p_{e} \sin (\omega t+\varphi) & \pi<\omega t \leq 2 \pi
\end{array}\right. \\
\left\{\begin{array}{c}
\dot{Z_{i n}}=\frac{\omega_{r}^{2} M^{2}}{\dot{Z}_{L}} \\
\dot{I}_{1}=\frac{V_{2}}{j \omega_{r} M} \\
\dot{I}_{2}=\frac{V_{1}}{j \omega_{r} M} \\
\dot{Z}_{L}=\frac{V_{2}}{-\dot{I}_{2}}=\left|Z_{L}\right| \angle \varphi
\end{array}\right.
\end{gathered}
$$

From (2), it can be found that the current source in series with the secondary-side is only depended on the input voltage and the mutual inductance with series compensation, which means the input of the active rectifier can be equivalent to an constant sinusoidal current source. Thus, at the specified operation frequency, the primary-side and secondary-side are decoupled by the compensation design, and the output regulation can be achieved only be secondary-side control. In this proposed structure, the primary-side inverter works at 0.5 duty-cycle condition and the switching frequency is set as a constant. At secondary-side, the switching frequency should be matched as the primary-side and the phase-shift control is conducted for both ourput regulation and primasy-side ZVS achievement.Thus not only the wireless communication can be eliminated for the system but also, the circuit design and optimization can be conducted only at one switching frequency. The key-wavefroms of the system are illustrated in Fig.5. The output current Io can be regulate by zvarphiand $D$ at secondary side as

$$
I_{o}=\frac{2 \sqrt{2} V_{g}}{j \omega_{r} M} \sin \left(\frac{D \pi}{2}\right)
$$

, where $I_{o}$ is the output current and $V_{g}$ is the input DC voltage of the system. The output voltage can be calculated with the corresponding load resistance. The output power can be calculated by

$$
P_{o}=\frac{\left|\dot{V}_{1}\right|\left|\dot{V}_{2}\right|}{\left|j \omega_{r} M\right|} \cos \left(\frac{\pi}{2}-\varphi\right)
$$

, from which the output can be regulated as introduced before.
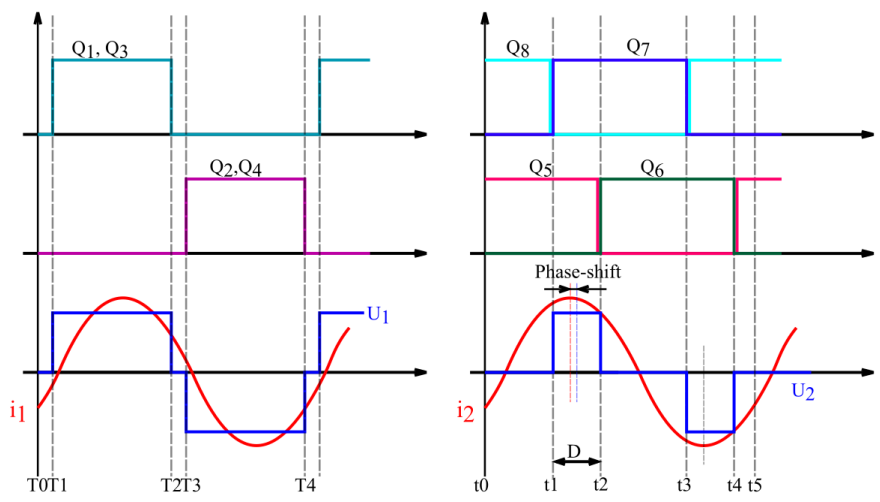

Fig. 5. Key waveforms of proposed IPT system.

\section{Soft-switching Achievement by Impedance Control}

The soft-switching can help to reduce the switching loss and EMI noise significantly and generally can be achieved by a reversed current at the switching node for a half-bridge configuration [10]. Conventionally in an IPT system with S-S compensation, a switching frequency modulation is adopted to keep the input impedance of the inverter as inductive for the soft-switching achievement [11]. In the proposed structure, the input impedance is controlled by the phase-shift angle $\varphi$ at a constant operation frequency while the compensation from the series capacitors is maintained. Based on the circuit model in Fig.4, the input impedance $Z_{i n}$ is given by

$$
\dot{Z}_{i n}=R_{1}+\frac{\omega_{r}^{2} M^{2}}{\dot{Z}_{L}+R_{2}}
$$

, and the equivaleng load impedance $Z_{L}$ is given by

$$
\dot{Z}_{L}=\frac{4}{\pi^{2}} R_{L}\left[1-\cos \left(\frac{2 \pi D}{\omega_{r}}\right)\right] \cos \varphi(\cos \varphi+j \sin \varphi)
$$

, where $R_{L}$ is the load resistance. In order to achieve ZVS turnon for the primary-side switches, the $Z_{i n}$ should be coutolled as inductive by the secondary-side phase-shift $\varphi$. The condition for minimized reactive power is given by

$$
\frac{\frac{4}{\pi^{2}} R_{L}\left[1-\cos \left(\frac{2 \pi D}{\omega_{r}}\right)\right] \cos \varphi \sin \varphi}{\omega_{r}}\left|I_{1}\right|^{2}=V_{g}\left(C_{o s s H}+C_{o s s L}\right)
$$

, where $C_{o s s H}$ and $C_{o s s L}$ are the output capacitance of the high-side and low-side switches correspondingly.

\section{HARDWARE DESIGN AND IMPLEMENTATION}

In this sectionm the analysis of inductive coupler and the design of secondary-side Zero-Crossing-Detection circuit are presented. The specification is set as maximum $330 \mathrm{~V} / 3 \mathrm{~A}$ output. The power transimmion distance is $100 \mathrm{~mm}$ based on the un-manned autonomous vehicles charging application. The 
operational frequency is selected as $120 \mathrm{kHz}$ based on the capability of switches, materials implemented on the coils and the power loss estimation.

\section{A. Inductive Coupler Analysis and Implementation}

The equavalent series resistance (ESR) and the coupling coefficient of the inductive coupler will directly determine the efficiency of the coils. First of all, the quality factor ( $Q$ factor) is defined for the coil as

$$
Q=\frac{\omega L}{r}
$$

, where $\omega$ is the freuqency during the operation and $L$ is the self-inductance of one coil. The loaded Q-factor is defined in series-series compensation as

$$
Q_{L}=\frac{\omega L_{2}}{R_{L}}
$$

, where $R_{L}$ is the resistance of the load. It is notice that the $Q_{L}$ is calculated by the final load $R_{L}$ rather than the equivalent load impedance $\left(Z_{L}\right)$ because the $R_{L}$ can only represent the power assumption by the load. Then the power transmission efficiency of the inductive coupler can be calculated by

$$
\eta_{\text {coupler }}=\frac{Q_{L 1} Q_{L 2}^{2} K^{2}}{\left(Q_{L 2}+Q_{L}\right)\left(Q_{L 1} Q_{L 2} Q_{L} K^{2}+Q_{L 2}+Q_{L}\right)}
$$

, where $Q_{L 1}$ and $Q_{L 2}$ are the Q-factor for the primary-side coil and the secondary-side coil and $K$ is the coupling coefficient of the coils. The partial derivation of the efficiency to the coupling co-efficient $K$ is given by

$$
\frac{\partial \eta_{\text {coupler }}}{\partial K}=\frac{2 Q_{L 1} Q_{L 2}^{2} Q_{L} K}{\left(Q_{L 1} Q_{L 2} Q_{L} K^{2}+Q_{L 2}+Q_{L}\right)^{2}}
$$

, based on which the efficiency of the inductive coupler (including the coils and the compensation capacitors) is shown as a function as the coupling coefficient in Fig.6.

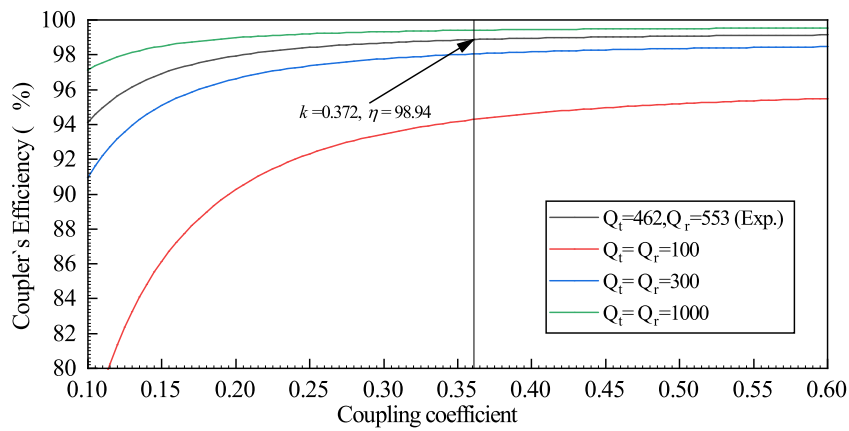

Fig. 6. Coupler's efficiency with different inductive coupler (operation frequency is $120 \mathrm{kHz}$ ).

An overview of the inductive coupler implemented in the system is given in Table I. In order to enhance the coupling between primary-side and secondary-side coils, customized ferrite plates are implemented on the couplers, whose geometry are illustrated in Fig.7 (a). The material of the plate is

\begin{tabular}{|c|c|c|}
\hline Parameters & Value & Comments \\
\hline Geometry $(\mathrm{H} / \mathrm{W} / \mathrm{H}$ in $\mathrm{mm})$ & $300 / 300 / 15$ & l \\
\hline Inner diameter of wires $(\mathrm{mm})$ & 200 & l \\
\hline Outer dismeter of wires $(\mathrm{mm})$ & 292 & l \\
\hline Number of turns & 21 & Litz wire 60 turns/ $0.1 \mathrm{~mm}$ \\
\hline Diameter of wire $(\mathrm{mm})$ & 1.2 & I \\
\hline \multirow[t]{2}{*}{ Inductance $(\mu H)$} & 314.15 & Primary-side \\
\hline & 292.43 & Secondary-side \\
\hline \multirow[t]{2}{*}{ Capacitance $(n F)$} & 2.60 & Primary-side \\
\hline & & Secondary-side \\
\hline \multirow{2}{*}{ ESR at $120 \mathrm{kHz}(m \Omega)$} & 512.5 & /Primary-side \\
\hline & 398.0 & Secondary-side \\
\hline \multirow[t]{2}{*}{ Compensation capacitor } & 20 & RF Ceramic capacitor \\
\hline & $1.2 \mathrm{nF} / 1000 \mathrm{~V}$ & $\begin{array}{l}10 \text { pieces in parallel as a set } \\
2 \text { sets in series }\end{array}$ \\
\hline Renonant frequency $(\mathrm{kHz})$ & 120 & l \\
\hline
\end{tabular}
DTT-P4. In Fig. 7 (b), the photo of one coupler is shown and
TABLE I

PARAMETER OVERVIEW OF THE INDUCTIVE COUPLER

it can be also fount that 12 pieces of the plates is combined as a ferrite disc on the back of the coils.

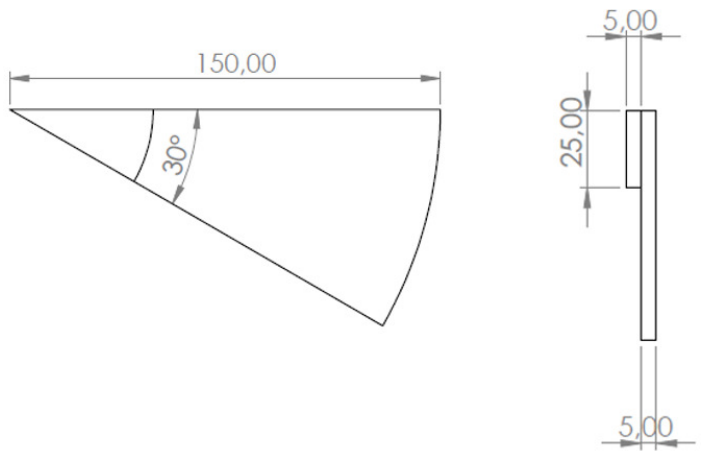

(a)

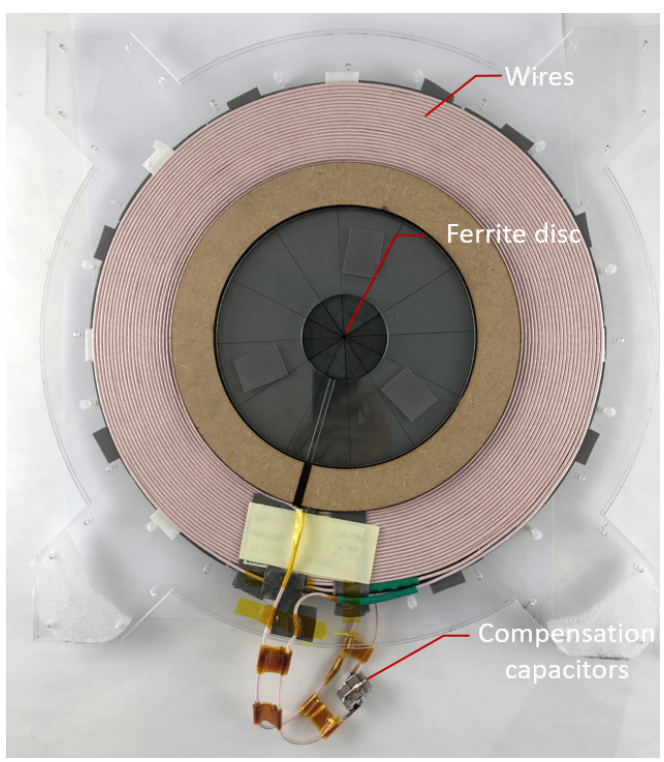

(b)

Fig. 7. (a) Geometry of the ferrite piece (b) Photo of one inductive coupler. 


\section{B. Phase and Frequency Detection at Secondary-Side}

Due to no wireless communication is adopted in the system, the switching frequency of the inverter and the time-base for the secondary control should be detected by the zerocross-detection (ZCD) circuit at the secondary side. In [12], [13], the shunt resistor is connected in series with detected current and the voltage on the shunt resistor is sampled by a comparator and transmitted to the controller. In Fig. 8 (a), a reference design is illustrated, which consists of the shunt resistor $R_{Z C D}$, a comparator $L V 7219$ and a magnetic isolator $A D u M 1100$. However, this ZCD circuit has several drawbacks during the implementation: firstly, this ZCD circuit need several isolated grounds to isolate the main power stage to the controller, which increase the difficulty of the PCB layout design; Besides, the increased number of power suppliers for the comparator and the isolator also increase the size and the cost of the ZCD circuit. In the design, a current transformer based ZCD circuit is designed for ZCD at the secondary-side, which is illustrated in Fig.8 (b).

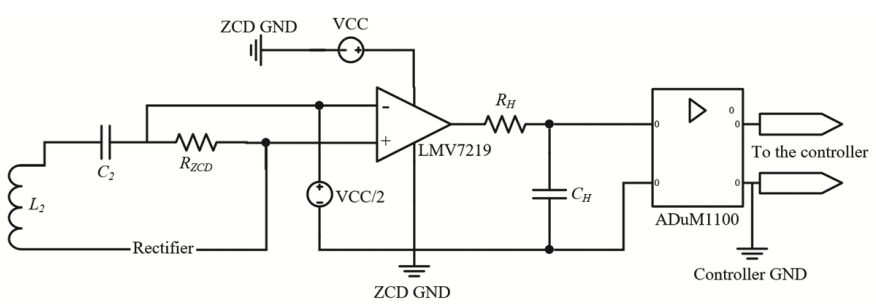

(a)

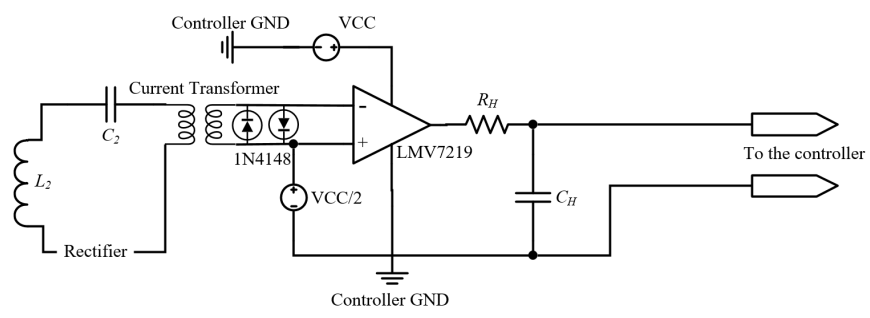

(b)

Fig. 8. (a) ZCD circuit with a shunt resistor (b) ZCD circuit with a current transformer.

In the current transformer based ZCD circuit, the secondaryside of the transformer is connected to two reversely paralled diode, thus when the primary-side current is a sinosoidal waveform, the voltage of the secondary-side should be a rectangular waveform, whose frequency is the same as the primary-side and the voltage will shift its pole when the simosoidal waveform crosses the zero. In our design the clamped diodes are seleted as 1N4148, whose forward voltage is higher than $0.5 \mathrm{~V}$. The turns ratio of the current tranformer is design based on the maximum repetitive forward current of the diode as

$$
\frac{1}{N}<\frac{I_{M P e a k}}{I_{F R M}}
$$

, where $\mathrm{N}$ is the number of turns on the secondary-side and the
TABLE II

KEY COMPONENTS OF THE PROTOTYPE.

\begin{tabular}{lll}
\hline \hline Parameter & Value & Description \\
\hline Q1-Q8 & C3M0065090 & 900 V SiC MOSFET \\
\hline Gate driver & Si8273 & Half-bridge gate driver \\
\hline \multirow{2}{*}{ DC capacitors } & LLS2G471MELC $\times 2$ & $\begin{array}{l}\text { ALUM capacitor } \\
\text { 400V/ 479uF }\end{array}$ \\
\cline { 2 - 3 } & B32673P5225K000 $\times 4$ & $\begin{array}{l}\text { Film capacitor } \\
\text { 400V/ 220uF }\end{array}$ \\
\cline { 2 - 3 } & C2225C474K $\times 8$ & $\begin{array}{l}\text { Ceramic capacitor } \\
\text { 200V/ 470nF in series }\end{array}$ \\
\hline Voltage sampling & ACS724 & $/$ \\
\hline Current sampling & ACPL_C87B & $/$ \\
\hline ZCD detection & LMV7219 & $/$ \\
\hline Controller & TMS320F28379 & DSP controller \\
\hline \hline
\end{tabular}

number of turns of the primary-side is normally chosen as 1 ; $I_{M \text { Peak }}$ is the peak value of the measured current and $I_{F R M}$ is the repetitive forward current of the diode. In our design, the $N$ is designed as 10 and a nanocrystaline core in toriadal shape to minimized the error from the leakage inductance.

\section{EXPERIMENTAL RESUlTS AND DISCUSSION}

An experimental prototype was built to verify the proposed IPT charging system, whose key-parameter is given in TableII. Dureing the testing, the primary-side inverter works at openloop state and the duty cycle is set as $47 \%$ thus during the dead-time the switches in the primary-side can ahcieve ZVS turn-on. The secondary switches are controlled by the controller DSP28379 and no wireless communication is implemented in the system.

Firstly, the performances of the system were tested under different input voltage at constant duty-cycle and phase-shift. The efficiency of the system is shown in Fig.9. The power transmission distance is $100 \mathrm{~mm}$. With the increasing input voltage, the power transmission capability is increased dut to the secondary-side current can be pushed. And also the efficiency peak is pushed at higher output power.

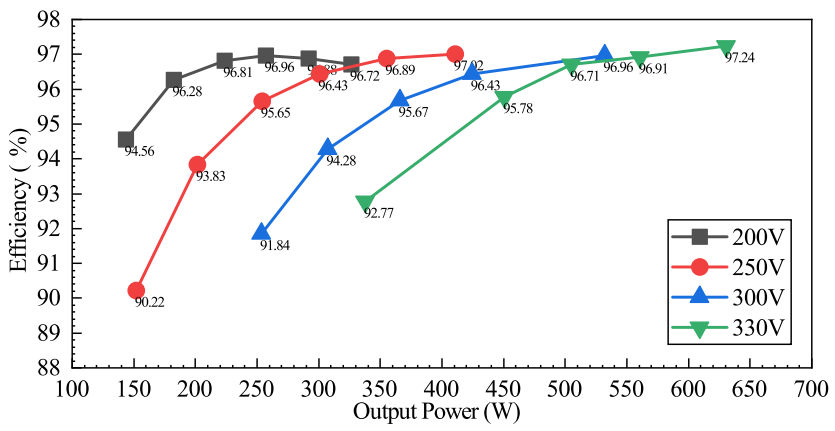

Fig. 9. Efficiency of the prototype with different input voltage.

A constant current output testing is also conducted on the system, in which the maximum output power is pushed to the rated $1 \mathrm{~kW}$ and $3.3 \mathrm{~A}$ output. The testing efficiency at $100 \mathrm{~mm}$ and $120 \mathrm{~mm}$ power transmission distance is shown in Fig.10. 
The peak efficiency of the system can achieve $97 \%$ at $850 \mathrm{~W}$ and $100 \mathrm{~mm}$ power transmission and at $1 \mathrm{~kW} / 12 \mathrm{~mm}$ power transmission, the efficiency can achieve $96.8 \%$. The thermal images for the inverter and rectifier are shown in Fig.11. It is noticed that at primary-side, the temperature rise for each switch is almost equal and due to the achievement of ZVS turn-on, the temperature rise is around $10^{\circ} \mathrm{C}$. At the secondary side, the temperature rise of half-bridge Q5/ Q6 is higher than that of half-bridge Q7/ Q8. The measurement waveforms are shown in 12 and the ZVS turn-on on the primaryside is verified.

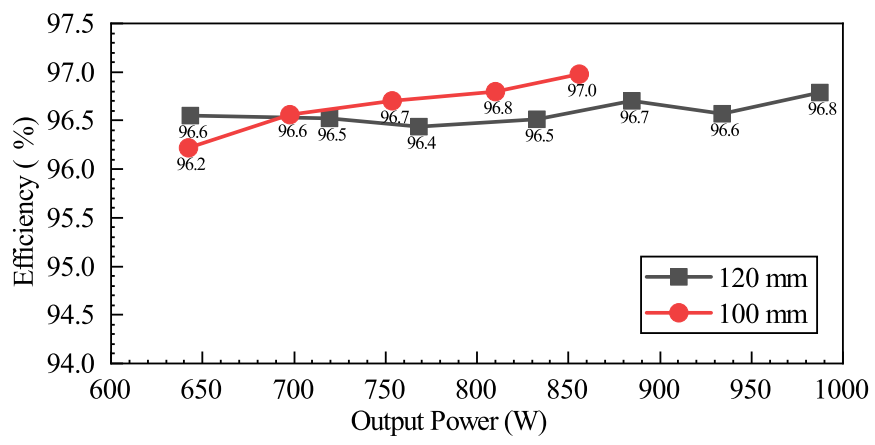

Fig. 10. Example of a figure caption.

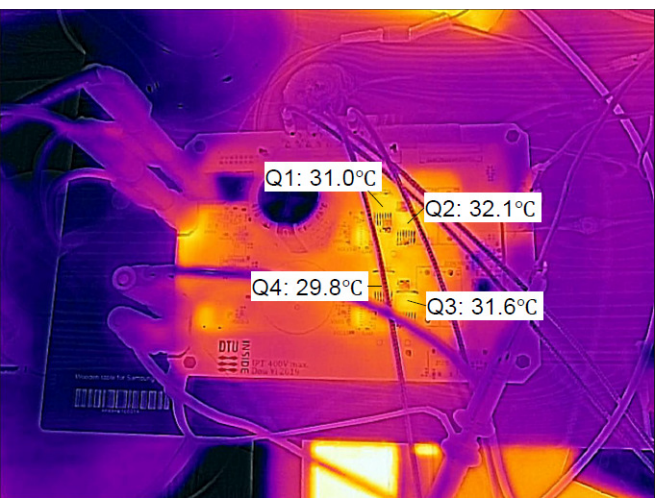

(a)

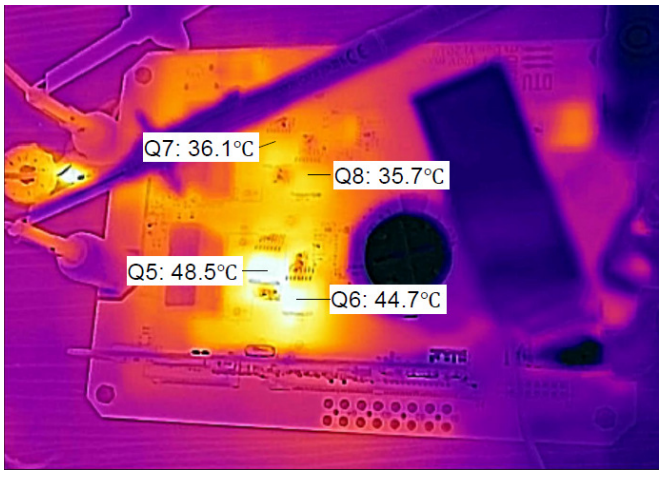

(b)

Fig. 11. (a) Thermal image of the inverter of the prototype (b) Thermal image of the rectifier of the prototype.

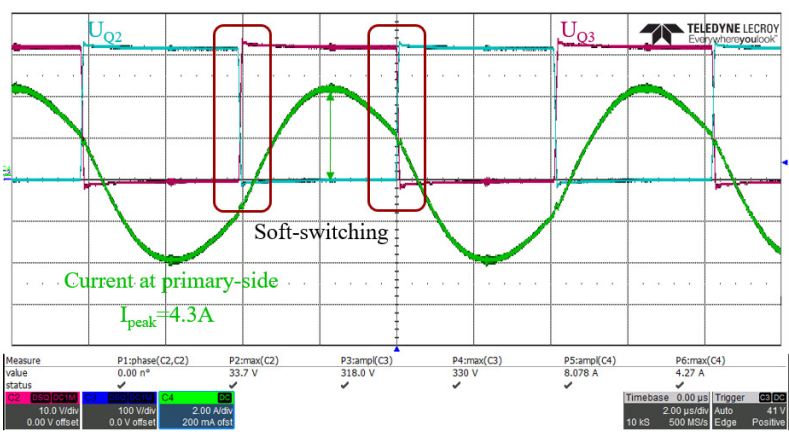

(a)

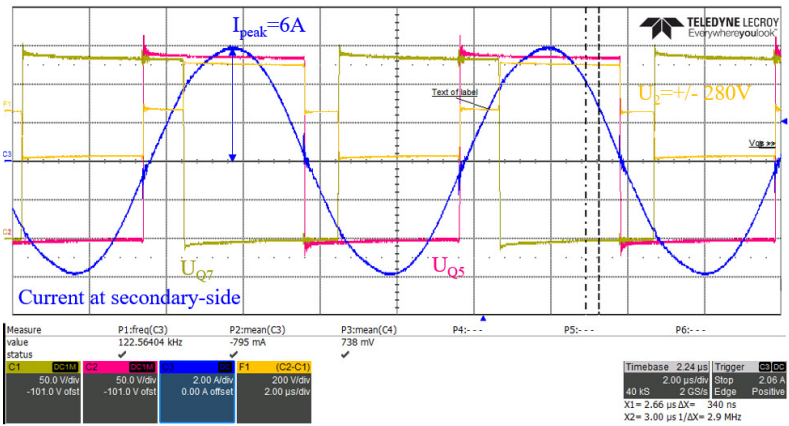

(b)

Fig. 12. (a) Measured waveform of the inverter (b) Measured waveform of the active revtifier.

\section{CONCLUSION}

This paper proposes a wireless power charging system with secondary-side output regulation method. By controling the secondary phase-shift and duty-cycle the converter can achieve the output regulation without wireless communication and the ZVS turn-on on the primary-side. Experimental results verifies the ZVS achievement and the output regulation in a high efficiency operation. Compared with the previous WPT system, the wireless communication can be eliminated and also the optized design can be conducted in a specified operational frequency.

\section{ACKNOWLEDGEMENT}

The authors would like to thank the Bs\&T Frankfurt am Main $\mathrm{GmbH}$ and Shandong Dongtai Electronic Science and Technology Co., China for providing the magnetic materials for the project.

\section{REFERENCES}

[1] R. Bosshard and J. W. Kolar, "Multi-Objective Optimization of 50 $\mathrm{kW} / 85 \mathrm{kHz}$ IPT System for Public Transport," in IEEE Journal of Emerging and Selected Topics in Power Electronics, vol. 4, no. 4, pp. 1370-1382, Dec. 2016

[2] R. Bosshard, J. W. Kolar, J. Mühlethaler, I. Stevanović, B. Wunsch and F. Canales, "Modeling and $\eta$ - $\alpha$-Pareto Optimization of Inductive Power Transfer Coils for Electric Vehicles," in IEEE Journal of Emerging and Selected Topics in Power Electronics, vol. 3, no. 1, pp. 50-64, March 2015

[3] H. Li, J. Li, K. Wang, W. Chen and X. Yang, "A Maximum Efficiency Point Tracking Control Scheme for Wireless Power Transfer Systems Using Magnetic Resonant Coupling," in IEEE Transactions on Power Electronics, vol. 30, no. 7, pp. 3998-4008, July 2015. 
[4] A. Berger, M. Agostinelli, S. Vesti, J. A. Oliver, J. A. Cobos and M. Huemer, "A Wireless Charging System Applying Phase-Shift and Amplitude Control to Maximize Efficiency and Extractable Power," in IEEE Transactions on Power Electronics, vol. 30, no. 11, pp. 6338-6348, Nov. 2015.

[5] T. Chan and C. Chen, "A Primary Side Control Method for Wireless Energy Transmission System," in IEEE Transactions on Circuits and Systems I: Regular Papers, vol. 59, no. 8, pp. 1805-1814, Aug. 2012.

[6] R. Mai, Y. Liu, Y. Li, P. Yue, G. Cao and Z. He, "An Active-RectifierBased Maximum Efficiency Tracking Method Using an Additional Measurement Coil for Wireless Power Transfer," in IEEE Transactions on Power Electronics, vol. 33, no. 1, pp. 716-728, Jan. 2018.

[7] Y. Jiang, L. Wang, Y. Wang, J. Liu, X. Li and G. Ning, "Analysis, Design, and Implementation of Accurate ZVS Angle Control for EV Battery Charging in Wireless High-Power Transfer," in IEEE Transactions on Industrial Electronics, vol. 66, no. 5, pp. 4075-4085, May 2019.

[8] Y. Jiang, L. Wang, Y. Wang, J. Liu, M. Wu and G. Ning, "Analysis, Design, and Implementation of WPT System for EV's Battery Charging Based on Optimal Operation Frequency Range," in IEEE Transactions on Power Electronics, vol. 34, no. 7, pp. 6890-6905, July 2019.

[9] F. Liu, W. Lei, T. Wang, C. Nie and Y. Wang, "A phase-shift softswitching control strategy for dual active wireless power transfer system," 2017 IEEE Energy Conversion Congress and Exposition (ECCE), Cincinnati, OH, 2017, pp. 2573-2578.

[10] S. Chen, H. Li and Y. Tang, "A Monotonic Output Regulation Method for Series-Series Compensated Inductive Power Transfer Systems with Improved Efficiency and Communication-Less Control," 2018 IEEE Energy Conversion Congress and Exposition (ECCE), Portland, OR, 2018, pp. 6173-6178.

[11] M. Kasper, R. M. Burkart, G. Deboy and J. W. Kolar, "ZVS of Power MOSFETs Revisited," in IEEE Transactions on Power Electronics, vol. 31, no. 12, pp. 8063-8067, Dec. 2016.

[12] Z. Liu, Z. Huang, F. C. Lee and Q. Li, "Digital-Based Interleaving Control for GaN-Based MHz CRM Totem-Pole PFC," in IEEE Journal of Emerging and Selected Topics in Power Electronics, vol. 4, no. 3, pp. 808-814, Sept. 2016.

[13] Z. Liu, F. C. Lee, Q. Li and Y. Yang, "Design of GaN-Based $\mathrm{MHz}$ Totem-Pole PFC Rectifier," in IEEE Journal of Emerging and Selected Topics in Power Electronics, vol. 4, no. 3, pp. 799-807, Sept. 2016. 